\title{
The Study of Corrective Feedback Strategy in College Spoken English Class
}

\author{
Si-si Liu \\ Department of College English, Guangdong University of Foreign Studies South China Business College, Guangzhou, \\ Guangdong 510000, China \\ Email:724192305@qq.com
}

\begin{abstract}
Numerous studies show that students of non-English major in China's colleges generally have a low level of spoken English with a large number of errors. This research aims to improve the effectiveness of corrective feedback strategy and thus improve the accuracy, appropriateness, fluency and reasonability of spoken English. According to the research findings in this field home and broad, the author discussed and summarized the application of corrective feedback strategy from its five core elements and offers some conclusions and suggestions as to whether and which errors should be corrected, when, how and who to correct them in the college spoken English class.
\end{abstract}

Keywords: College English, Spoken English class, Corrective feedback strategy.

\section{INTRODUCTION}

The new syllabus of College English requires students to be equipped with the ability to communicate rather than just gaining information. English speaking ability is essential for communicating information and feelings. However, numerous researches have shown that college students of non-English majors in China make substantial errors when speaking English, which seriously damages the communication effectiveness. Few research had been conducted on how to deal with these errors in the college spoken English class in a comprehensive way based on the five core elements of corrective feedback strategy. This research discusses these core elements of corrective feedback strategy in the college spoken English classroom in order to enhance the efficiency of error correction and improve the accuracy, appropriateness, fluency and reasonableness of students' spoken English.

\section{NECESSITY OF CORRECTIVE FEEDBACK}

Researches on corrective feedback strategy in foreign language teaching started from 1970s, of which five aspects, namely whether errors should be corrected, which types of them should be corrected, when, how and who to correct them, put forward by Hendrickson (1978) [1], are at the core.
Schmidt (1990) believed that second language acquisition is a process of conscious learning, of which selective noticing is the key and corrective feedback is one way of triggering noticing [2]. Corrective feedback enable learners to adjust, rebuild their interlanguage and formulate correct output. In addition, many researches on college students' belief in the corrective feedback in the spoken English classes show that they welcome the corrective feedback [3] and they hope that their errors will be corrected and they can make improvements through the correction [4].

Based on these results, this research also believes that errors should be corrected and will continue to analyze the other four core elements of the corrective feedback --- which types of errors should be corrected, when, how and who to correct them.

\section{DISCUSSION ON CORRECTIVE FEEDBACK STRATEEGY IN SPOKEN ENGLISH CLASSES}

\subsection{Which Types of Errors Should Be Corrected}

The author has conducted a research on the error analysis of the spoken interlanguage of 80 college students of non-English major and found that phonetic, lexical and grammatical errors account for $60 \%, 19.5 \%$ 
and $20.5 \%$ respectively [5]. Should all these types of errors be corrected? According to an empirical study, the type of errors students would like to be corrected most is phonetic errors, followed by lexical errors and grammatical errors because they believe that phonetic and lexical errors would impact the effectiveness of communication while some insignificant grammatical errors would not [3]. This study also shows that students pay little attention to pragmatic errors and they only focus on the errors that have incorrect linguistic forms instead of unreasonable content. This has been verified by other researchers. Lin's research also finds that students hope their phonetic errors would be corrected compared to grammatical and lexical errors [4].

Therefore, teachers should respond to students' concerns and correct the phonetic errors in classes and lecture about the common errors, such as those phonemes that do not exist in Chinese--- $/ \theta /, / \mathrm{v} /, / \mathrm{J} /, / \mathrm{d} /$, $/ 3 /, / æ /$. Whether to correct lexical and grammatical errors should depend on the fact that they are local or global errors. If they are global errors which affect the meaning of the whole sentence and cause confusion, teachers should correct them to achieve the effectiveness of the classroom communication It is because of our exam-oriented education that our students attach little importance to pragmatic errors and errors in terms of content, logic and context. However, "enhancing intercultural communication awareness and ability" has been emphasized in our government document The Guide to College English Teaching and characteristics of being high-level, innovative and challenging are set up by our national education department to construct golden courses. All of these require teachers to pay more attention to pragmatic errors and errors of logic and improve the appropriateness and reasonability and cultivate their logical and critical thinking.

In the end, teachers need to distinguish errors and mistakes. For those that sometimes appear right and other times wrong, teachers can regard them as mistakes caused by non-cognitive factors such as stress and fatigue and do not correct them.

\subsection{When to Correct Errors}

Ellis and Sintani (2014) argued that instant and delayed corrective feedback may contribute in different ways to the second language acquisition. According to them, instant feedback benefits learning of procedural knowledge while delayed feedback promotes learners' understanding of metalinguistic knowledge [6]. From students' perspective, most students prefer to be corrected instantly because they argue they still remember clearly, while some students would rather be corrected when they finish speaking and there are still others who think when to correct errors should depend on different types of tasks. When they are making conversations, errors can be corrected immediately and when they are making a speech, correction should be made after they finish the speech [3].

Teachers need to strike a balance between instant and delayed corrective feedback in line with their advantages and students' preferences. According to $\mathrm{Zu}$ Xiaomei and Dengkui (2019), it is recommended that instant feedback are used when teachers and students are communicating by offering positive example and counter-example to make students notice the difference between their output and the target language and providing students opportunities to adjust their output to facilitate the learning of implicit knowledge and the development of communicative ability [7]. Adopt delayed corrective feedback strategy after students finish the speech or conversation between each other to ensure the fluency and improve their metalinguistic awareness and the explicit knowledge.

\subsection{How to Correct Errors}

Corrective feedback strategy includes reformulation and prompt. Reformulation means teachers correct the error with a correct form and prompt refers to asking students to correct their errors themselves by giving a hint [8]. Prompt involves different ways of negotiation like clarification, metalinguistic clues, enlightening and repetition to help learners correct their own errors[9](Figure 1). Choosing which strategy so as to achieve the best effect is determined by multiple factors, such as linguistic forms of the errors and individual characteristics.

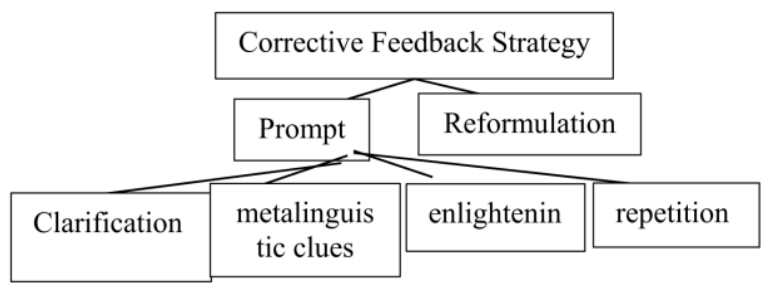

Figure 1 Types of corrective feedback strategy

\subsubsection{Choosing Different Corrective Feedback Strategy for Errors of Different Linguistic Forms}

Kim\&Han (2007) pointed it out that choosing which corrective feedback strategy depends on the significance of the linguistic forms and learners' processing procedures of different language rules [10]. According to Sheen, reformulation of phonetic and lexical errors induces a high rate of reaction and correction [11]. Lu Xiwen and Gao Liqun (2015) also found that reformulation benefits learning of pronunciation better than vocabulary and grammar because on one hand pronunciation, vocabulary and grammar have decreasing significance and on the other hand learners' processing of grammar is more 
complicated and longer than that of pronunciation and vocabulary [12]. Yang\&Lyster (2010) found prompt is more helpful than reformulation in learning the past tense of regular verbs and there is no significant difference between prompt and reformulation in learning the past tense of irregular verbs [13]. All of these show that the strategy of prompt is more efficient for learning regular linguistic rules because it helps learners to extract the rules of the target language in their long-term memory while the strategy of reformulation is more efficient for learning exemplificative linguistic forms because it offers positive examples.

Based on these research results, it can be seen that in college spoken English classes, teachers can use the strategy of reformulation to correct phonetic and lexical errors and the exemplificative grammatical errors to achieve a better corrective effect and use the strategy of prompt such as the metalinguistic clues to correct the errors involving regular rules and complicated grammar to strengthen students' understanding of the rules. It is important to mention that when reformulating, especially in meaning-centered communicative classes, teachers need to let students realize the real intention, which is correction, rather than just paraphrasing what the students have said. One way of doing that is repeating the error first to attract attention and then giving the correct output, or using the tone to imply the corrective intention of the reformulation.

\subsubsection{Choosing Different Corrective Feedback Strategy for Learners of Different Individual Characteristics}

Learners' individual characteristics play an important role in determining which corrective feedback strategy to choose, including the language proficiency, cognitive styles, learning motives and emotional reactions.

Many empirical researches show that learners of high language proficiency benefit more from the strategy of reformulation and learners of low language proficiency benefit more from the strategy of prompt because the former can realize their errors from the reformulation and the latter need specific prompt to help them realize their errors and then make the correction.

Cognitive styles are the distinctive and stable ways of processing and organizing information when people perceive, think, memorize and solve problems, the most common of which are field-independent and field-dependent according to Witkin \& Goodenough (1981). Field-independent people tend to use internal reference to process information while field-dependent people tend to use external reference and they are easily affected by other people, especially the authorities.
Field-independent students will benefit more from the strategy of prompt because they can make the correction themselves by extracting the right forms from their memory. The strategy of reformulation is more suitable for field-dependent students because the correction from others will be more impressive for them.

Dekeyser (1993) claimed that learners of strong motives and low level of anxiety gain more from corrective feedback [14]. Some students are more likely to feel anxious when being corrected, especially those with low self-efficacy. For them, it is better to adopt the strategy of reformulation instead of prompt so they do not need to correct the errors themselves and thus feel less stressed. And it is better to give the corrective feedback after they finish their tasks or even after class in private so as to avoid causing anxiety and protect their initiative. Teachers had better avoid using negative expressions like "You are wrong", establish a relaxing, delightful and positive atmosphere and build a friendly and equal relationship with students to relieve their anxious emotion.

\subsubsection{Mixing Different Types of Feedback Strategy}

Teachers need to mix different types of feedback strategy when teaching spoken English because not a single type is proved to be the most effective. Teachers can repeat the error or clarify the requirement to make students realize their errors, then provide metalinguistic clues with an example to deepen their understanding of the rules, make them correct their errors at last. This is in accordance with the Zone of Proximal Development by the social-cultural school which advocates that different kinds of corrective feedback strategy should be offered gradually so that learners can utter the correct forms of target language without others' help ultimately.

\subsection{Who to Correct Errors}

Peer assessment has become a hotspot for research on second language acquisition. Numerous studies show that peer assessment is conducive to second language acquisition. Under peer assessment, students not only focus on their own errors, but also are provided with opportunities to pay attention to and correct others' errors. This intensified attention and more chances to make correction cannot be provided under the environment where only teachers make corrections.

Although peer assessment are advocated by the government in China, it is not implemented on a large scale [15]. According to Zhou Jiming and Shu Dingfang (2019), it is not accepted well by students because on one hand they believe assessment should be given by teachers and they do not trust their peers for they are not professional or fair; on the other hand they cannot 
understand the assessing standard well so they are not able to assess their peers correctly [16].

Hence, teachers should make students realize the benefits of peer assessment, create a relaxing and cooperative learning atmosphere, give them the opportunities and power to help their peers correct errors, train them on corrective feedback strategy and strengthen their confidence. Teachers should also communicate with students about their feelings when they make correction for other students or are corrected by other students, improve their ability of resisting frustration and avoid that they refuse to give corrective feedback because they are worried that their feedback may be not correct. And at last, teachers should give feedback to the corrective feedback given by students.

\section{CONCLUSION}

There is no doubt that corrective feedback plays a significant role in second language acquisition but which types of errors to correct, when, how and who to correct errors will impact the effectiveness.Through analyzing and summarizing the research findings in this filed in recent years from home and abroad, it can be concluded that:

In college English spoken class, errors that need to be corrected include: phonetic errors, lexical and grammatical errors that will cause difficulties or misunderstanding in communication, pragmatic errors and errors in terms of content, logic and context.

As to the timing, teachers can give corrective feedback immediately when they are communicating with students and adopt delayed strategy when students are conducting conversation or giving speeches.

How to correct errors depend on the linguistic forms of errors and learners' characteristics. For phonetic and lexical errors and exemplificative grammatical errors, the strategy of reformulation is recommended. For grammatical errors of regular forms and complicated grammatical errors, the strategy of prompt, such as metalinguistic clues is suggested. Reformulation works better for students who are of high level or field dependent and prompt for those who are of low level or field independent. Students who get anxious easily are benefited more from delayed reformulation. In addition, teachers should mix the use of different types of strategy according to the situation.

Besides teachers' corrective feedback, peers' corrective feedback to each other has been proved effective in second language acquisition. Training and communication between teachers and students are in need to empower students to participate in correcting peer's errors and improve their ability of using corrective feedback strategy.

\section{ACKNOWLEDGMENTS}

This research is sponsored by the college project The Study of Spoken Interlanguage from Students of Non-English Major in Independent Colleges on the Basis of Error Analysis Theory (Grant No. 19-020B) as a sub-project of the Key Program of the English Language and Literature of Guangdong Province, 2016.

\section{REFERENCES}

[1] Hendrickson, J.(1978). Error Corrections in Foreign Language Teaching: Recent Theory, Research and Practice. Modern Language Journal, 8, 387-398.

[2] Schmidt, R.W.(1990). The Role of Consciousness in Second Language Learning. Applied Linguistics, $11,17-46$.

[3] Zhu, Y.(2016). Research on College English Learners' Belief in Oral Corrective Feedback. Foreign Languages and Their Teaching, 1, 33-40.

[4] Lin, L.L.(2006). An Investigation into the Perspections of Error Correction in Oral English Teaching. Journal of Hefei University of Technology, 3, 138-145.

[5] Liu, S.S.(2019).The Study of Spoken Interlanguage from Students of Non-English Major in Independent Colleges on the Basis of Error Analysis Theory. Proceedings of International Symposium on Second Language, 94-100.

[6] Ellis, R. \& Natsuko Shintani.(2014). Exploring Language Pedagogy through Second Language Acquisition Research. Routledge.

[7] Zu, X.M.\&Deng, K.(2019). Principles for Corrective Feedback Based on Second Language Acquisition Theories and Research Findings.Chinese Teaching in the World, 1, 117-129.

[8] Lyster, R.\&Saito, K.(2010). Oral Feedback in Classroom SLA:a Meta-analysis. Studies in Second Language Acquisition, 2, 265-302.

[9] Lyster, R.\& Ranta, L.(1997). Collective Feedback and Learner Uptake: Negotiation of Form in Communicative Classrooms, Studies on Second Language Acquisition, 1, 37-66.

[10] Kim, J. H\&Han, Z. H.(2007). Conversational Interaction in SLA: A collection of Empirical Studies, Oxford University Press.

[11] Sheen, Y.(2006). Exploring the Relationship between Characteristics of Recasts and Learner Uptake. Language Teaching Research, 4, 361-392. 
[12] Lu, X.W.\&Gao, L.Q.(2015). Impacts of Corrective Feedback on Acquisition in the Teaching of Chinese as a Foreign Language.Chinese Teaching in the World, 1.

[13]Yang, Y.\&Lyster, R.(2010). Effects of Form-focused Practice and Feedback on Chinese EFL Learners' Acquisition of Regular and irregular past tense forms. Studies in Second Language Acquisition, 2, 235-263.

[14] DeKeyser, R. M.(1993). The Effect of Error Correction on L2 Grammar Knowledge and Oral Proficiency. Modern Language Journal, 1, 501-514.

[15] Liu, J.D.(2015). Research on Foreign Language Assessment based on the Criteria. Foreign Language Teaching and Research,3, 417-425.

[16] Zhou, J.M.\&Shu, D.F.(2019).An Interactive Research on Teachers' Practice and Students' Cognition in Peer Assessment. Foreign Language World, 5, 64-71. 